\title{
The theoretical description for the electrochemical determination of 4-4'-dihydroxyazobenzene, assisted by a composite of squaraine dye with Cobalt (III) oxyhydroxide in pair with Cobalt (IV) oxide
}

\author{
Volodymyr V. Tkach ${ }^{1,2, *}$, Marta V. Kushnir ${ }^{1}$, Oleksandra V. Ahafonova ${ }^{3}$, Mariia P. Mytchenok ${ }^{3}$, Andrii \\ V. Bocharov ${ }^{3}$, Petro Ye. Kovalchuk ${ }^{3}$, Sílvio C. De Oliveira ${ }^{2}$, Petro I. Yagodynets ${ }^{1}$, Zholt O. Kormosh ${ }^{4, *}$, \\ Lucinda Vaz dos Reis ${ }^{5}$, Yulia L. Bredikhina ${ }^{6,7}$, Yana G. Ivanushko ${ }^{3}$ and \\ Yevgeniya V. Nazymok ${ }^{3}$ \\ ${ }^{1}$ Chernivtsi National University, 58000, Kotsyubyns'ky Str. 2, Chernivtsi, Ukraine \\ ${ }^{2}$ Universidade Federal de Mato Grosso do Sul, Av. Sen. Felinto. Müller, 1555, C/P. 549, 79074-460, Campo \\ Grande, MS, Brazil \\ ${ }^{3}$ Bukovinian State Medical University, 58000, Teatral'na Sq. 9, Chernivtsi, Ukraine \\ ${ }^{4}$ East Ukrainian National University, 43000, Voli Ave., 13, Lutsk, Ukraine \\ ${ }^{5}$ Universidade de Trás-os-Montes e Alto Douro, Quinta de Prados, 5001-801, Folhadela, Vila Real, Portugal \\ ${ }^{6}$ Melitopol State Pedagogical University, 72300, Hetmanska Str, 20, Melitopol, Ukraine \\ ${ }^{7}$ Khortytsya National Rehabilitation Academy, 69000, Naukove Mistechko Str., 59, Zaporizhzhia, Ukraine
}

\begin{abstract}
The theoretical description for 4-4'-dihydroxyazobenzene $\mathrm{CoO}(\mathrm{OH})$ - assisted electrochemical determination in the mushroom pulp, food, and biological liquids has been described. In this system, a squaraine dye is used as a Cobalt(III)oxyhydroxide stabilizer and electron transfer mediator. It is shown that, contrary to the large part of the systems with Cobalt (III) oxyhydroxide, this system will behave more stably, providing an efficient diffusion-controlled process. On the other hand, the oscillatory and monotonic instabilities, although possible, are caused by the double electric layer influences of either chemical or electrochemical stage.
\end{abstract}

Keywords: food safety; Agaricus xanthodermus; 4-4'-dihydroxyazobenzene; Cobalt(III)oxyhydroxide; squaraine dye; electrochemical sensors; stable steady-state.

\section{Introduction}

Agaricus is the most cultivated and consumed genus of mushrooms in Western and Northern Europe ${ }^{1-4}$. Its principal and most known representants are button mushroom (Agaricus bisporus) and field mushroom (Agaricus campestris). Both of them are edible and are cultivated in specialized farms.

Nevertheless, alongside with the edible species, this genus includes also some poisonous species. The most common of them is the so-called yellow stainer (Agaricus xanthodermus). It may readily grow among the edible Agaricus mushrooms and even compart the same mycelium, so it is easy to be confounded with the button and field mushrooms. Of those who gather Agaricus mushrooms, the yellow stainer poisoning cases are nearly half of the total of the mushroom intoxications. The yellow stainer may be discriminated among the rest of the Agaricus mushroom by color and disgusting smell, which becomes even more intense on cooking. Either the color or the smell or the toxic effects of the mushroom for most people are explained by the presence of the phenolic compounds in it. The most toxic of these phenolic compounds ${ }^{5-8}$ is the 4-4'-dihydroxyazobenzene (Figure 1), which is responsible for the color of the mushroom. It was the first naturally found endogenous azo-dye.

In the mushroom pulp, the phenolic compounds act as antioxidants, detaining the metabolic oxidation processes. Nevertheless, containing an actively accepting azo-group, this compound becomes much more acidic, while compared to the simplest phenol, and its ingestion may cause gastric problems. Moreover, the 4-4'-dihydroxyazobenzene also has a potential to be used as an industrial dye, being intentionally or unintentionally added into food. Thus, the development of the determination methods for $4-4^{\prime}$-dihydroxyazobenzene is actual. 


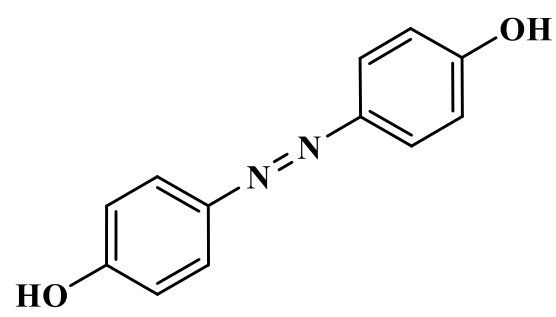

Figure 1. 4-4'-dihydroxyazobenzene

As for now, no chemical or electrochemical methods, capable of determining accurately the 4-4' dihydroxyazobenzene have been described. Nevertheless, from the chemical composition of the compound, it is possible to foresee that, as other phenolic and hydroquinone compounds, it will be electrochemically active ${ }^{9-14}$ for either cathodic or anodic determination. Its behavior has to be similar to that of either Sudan dyes or hydroquinone compounds.

For the case of anodic oxidation, the use of the Cobalt (III) oxide-hydroxide may be suggested. It is a p-type semiconductor, proposed by some researchers as an alternative to titanium dioxide ${ }^{15-18}$, but with more flexible electrochemical behavior. Possessing trivalent Cobalt, it may act either as an oxidant or as a reductant. Both redox pair may be applied to the phenolic compounds. Its electroanalytical behavior has been analyzed by either experimental ${ }^{19-22}$ or theoretical ${ }^{23-26}$ means.

For stability reasons, Cobalt (III) oxide-hydroxide may be used as a part of composite material with the conducting polymer, carbon material, or a squaraine dye. Thus, the Cobalt (III) oxide-hydroxide acts as an active substance, and the conjugated material, as a mediator.

Nevertheless, the use of novel electrode modifiers with novel analytes may be impeded by:

- The indecision concerning the exact mechanism of electrochemical reaction;

- The necessity of determination of the parameter region, correspondent to the most efficient active substance and mediating action;

- The presence of electrochemical instabilities, yet described for the $\mathrm{CoO}(\mathrm{OH})$ synthesis ${ }^{27-28}$.

The mentioned problems may only be solved employing an analysis of a mathematical model capable of describing the 4-4'-dihydroxyazobenzene electrochemical determination adequately. Moreover, it is also capable compare the behavior of this system with that for similar ones without any experimental essay.

So, the goal of this work is the mechanistic theoretical analysis of the 4-4'-dihydroxyazobenzene electrochemical determination, assisted by $\mathrm{CoO}(\mathrm{OH})$
- Squaraine dye composite. To achieve it, we realize the specific goals:

- The suggestion of the mechanism of the reaction consequence, leading to the appearance of an analytical signal;

- Development of the balance equation mathematical model, correspondent to the electroanalytical system;

- Analysis and interpretation of the model in terms of the electroanalytical use of the system;

- The seek for the possibility of electrochemical instabilities and the factor, causing them;

- The comparison of the mentioned system's behavior with a similar one ${ }^{27-28}$.

Two types of behavior are possible, depending on the redox role of Cobalt(III)oxide-hydroxide. In this work, the use of $\mathrm{CoO}(\mathrm{OH})-\mathrm{CoO}_{2}$ redox pair is analyzed. The behavior, in this case, will be more exciting than in the case of the use of $\mathrm{CoO}(\mathrm{OH})$ as oxidant.

\section{System and its modeling}

In the case of the use of $\mathrm{CoO}(\mathrm{OH})-\mathrm{CoO}_{2}$ redox pair, both quinonic oxidation and assisted polymerization of the 4-4'-dihydroxyazobenzene are possible. Thus, the electroanalytical process will be schematically described in Figure 2. In the simplest case, both participants of the quinonic compound in the polymerization process and the polymer oxidation aren't included.

For the potentiostatic mode, the electroanalytical process will be described by the balanced differential equation set of two variables:

$p$ - phenolic compound concentration in the presurface layer;

c - Cobalt (III) oxide-hydroxide - dye composite surface coverage degree.

To simplify the modeling, we suppose that the reactor is intensively stirred, so we can neglect the convection flow. Also, we assume that the background electrolyte is in excess so that we can ignore the migration flow. The diffusion layer is supposed to be of a constant thickness, equal to $\delta$, and the concentration profile in it is supposed to be linear. 


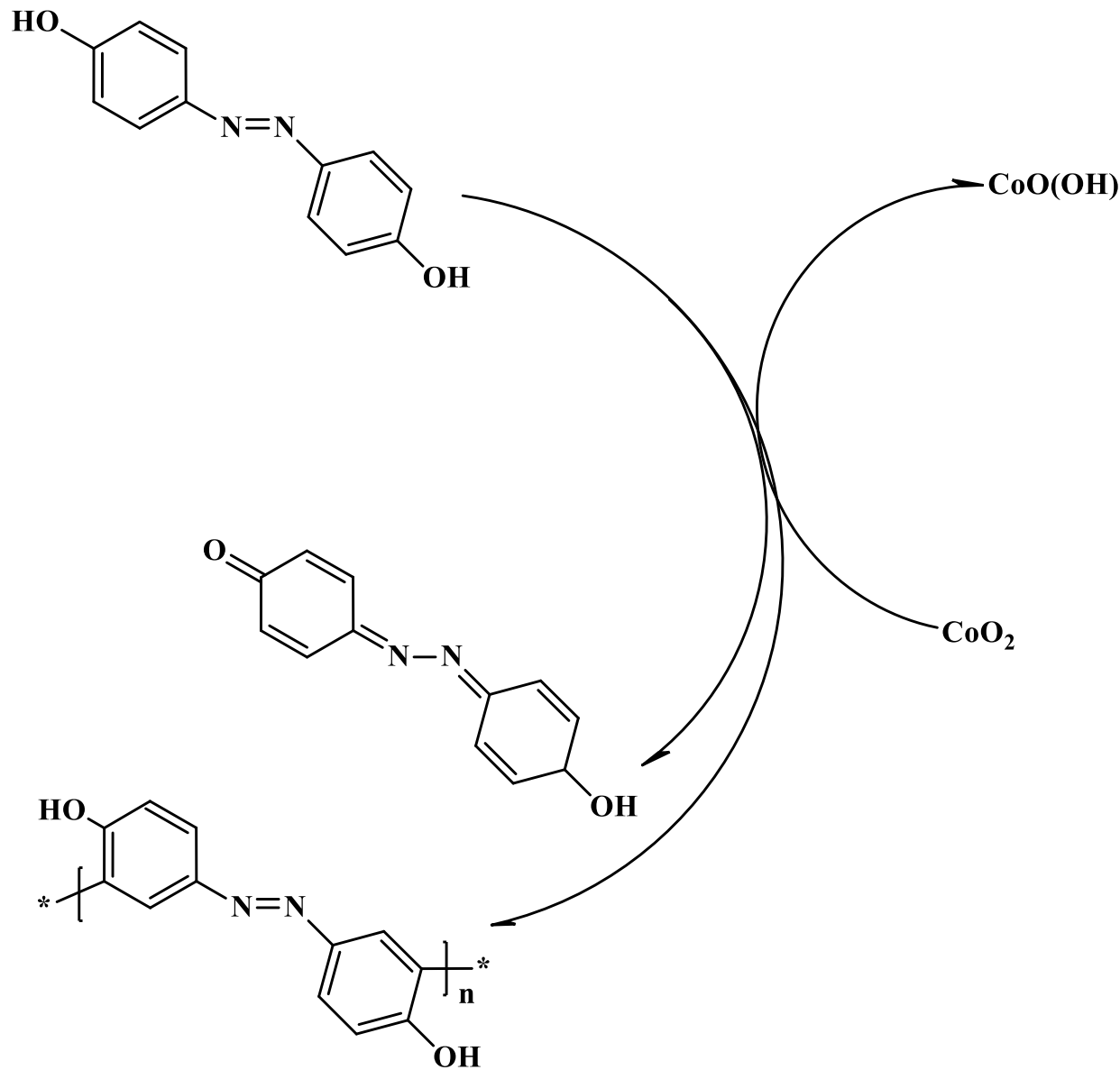

Figure 2. The scheme of the electroanalytical process

The dye diffuses towards the pre-surface layer and reacts with Cobalt dioxide. It is capable of oxidizing either by the quinone-hydroquinonic way, yielding a micromolecule, or by electropolymerization, yielding a macromolecule. Either way, $\mathrm{CoO}(\mathrm{OH})$ is restored. It is oxidized, regenerating $\mathrm{CoO}_{2}$ by the electrochemical way. Thus, the behavior of this system will be described by the equation set:

$\left\{\begin{array}{c}\frac{\mathrm{dp}}{\mathrm{dt}}=\frac{2}{\delta}\left(\frac{\mathrm{P}}{\delta}\left(\mathrm{p}_{0}-\mathrm{p}\right)-\mathrm{r}_{1}-\mathrm{r}_{\mathrm{p}}\right) \\ \frac{\mathrm{dc}}{\mathrm{dt}}=\frac{1}{\mathrm{C}}\left(\mathrm{r}_{1}+\mathrm{r}_{\mathrm{p}}-\mathrm{r}_{2}\right)\end{array}\right.$

in which $\mathrm{P}$ stands for the diffusion coefficient, $\mathrm{p}_{0}$ is the bulk concentration of the phenolic compound, C is the $\mathrm{CoO}$ maximal concentration in the pre-surface layer; $i_{F}$ is the Faradaic current and the parameters $r$ are the correspondent reaction rates, which may be calculated as:

$$
\begin{aligned}
& r_{1}=k_{1} p(1-c)^{2} \exp (-\alpha p) \\
& r_{p}=k_{p} p^{x}(1-c)^{y} \exp (-\alpha p) \\
& r_{2}=k_{2} c \exp \frac{F \varphi_{0}}{R T}
\end{aligned}
$$

in which the parameters $\mathrm{k}$ are the correspondent rate constants, $\alpha$ describes the DEL influence of the transformation of a more ionic phenolic compound to a less ionic quinonic form, which is significant for the relatively acidic phenols, $\mathrm{F}$ is the Faraday number, $\mathrm{R}$ is the universal gas constant, and $\mathrm{T}$ is the absolute temperature.

While compared to the use of the $\mathrm{CoO}(\mathrm{OH})-\mathrm{CoO}$ redox pair, the tetravalent Cobalt will be far much more active. Even for the simplest case, the oscillatory and monotonic instabilities will be more probable, as more processes are influencing the double electric layer, as shown below.

\section{Results and Discussions}

To investigate the steady-state stability of the system with the 4-4'-dihydroxyazobenzenem, assisted by Cobalt (III) oxide-hydroxide in pair with Cobalt dioxide, we analyze the equation-set (1) using the linear stability theory. The steady-state Jacobian matrix members may be exposed as:

$\left(\begin{array}{ll}a_{11} & a_{12} \\ a_{21} & a_{22}\end{array}\right)$

in which: 


$$
\begin{aligned}
& a_{11}=\frac{2}{\delta}\left(-\frac{P}{\delta}-k_{1}(1-c)^{2} \exp (-\alpha p)+\alpha k_{1} p(1-c)^{2} \exp (-\alpha p)-x k_{p} p^{x-1}(1-c)^{y} \exp (-\alpha p)+\right. \\
& \left.\alpha k_{p} p^{x}(1-c)^{y} \exp (-\alpha p)\right) \\
& a_{12}=\frac{2}{\delta}\left(2 k_{1} p(1-c) \exp (-\alpha p)+y k_{p} p^{x}(1-c)^{y-1} \exp (-\alpha p)\right) \\
& a_{21}=\frac{1}{c}\left(k_{1}(1-c)^{2} \exp (-\alpha p)-\alpha k_{1} p(1-c)^{2} \exp (-\alpha p)+x k_{p} p^{x-1}(1-c)^{y} \exp (-\alpha p)-\right. \\
& \left.\alpha k_{p} p^{x}(1-c)^{y} \exp (-\alpha p)\right) \\
& a_{22}=\frac{1}{c}\left(-2 k_{1} p(1-c) \exp (-\alpha p)-y k_{p} p^{x}(1-c)^{y-1} \exp (-\alpha p)-k_{2} \exp \frac{F \varphi_{0}}{R T}-j k_{2} c \exp \frac{F \varphi_{0}}{R T}\right)
\end{aligned}
$$

All the three reactions (both of the chemical stages and the electrochemical stage) influence the double electric layer capacitance. These influences may include a positive callback, responsible for oscillatory behavior.

According to Hopf bifurcation conditions, the oscillatory behavior is realized if $\operatorname{Tr} \mathrm{J}=0$ and Det $\mathrm{J}>0$. The first condition may be realized if the main diagonal contains at least one positive element. In this system, there are three positive elements $-\alpha k_{1} p(1-$ $c)^{2} \exp (-\alpha p)>0$ and $\alpha k_{p} p^{x}(1-c)^{y} \exp (-\alpha p)>$ 0 , if $\alpha>0$, describing the DEL influences of the chemical stages and $-j k_{2} c \exp \frac{F \varphi_{0}}{R T}>0$ if $\mathrm{j}<0$, describing the DEL capacitance changes of the electrochemical reaction. The intensity of all of these influences strongly depends on the support of electrolyte composition. Nevertheless, in general features, the oscillations are frequent and of small amplitude. Mathematically, the oscillatory behavior condition will be described as:

$$
\left\{\begin{array}{c}
-\frac{2}{\delta}(\kappa+\Xi)-\frac{1}{M}(P+\Omega)=0 \\
\kappa P+\Xi P+\kappa \Omega>0
\end{array}\right.
$$

Where:

$$
\frac{P}{\delta}=\kappa
$$

$k_{2} \exp \frac{F \varphi_{0}}{R T}-j k_{2} c \exp \frac{F \varphi_{0}}{R T}=\Omega$

To obtain the steady-state stability requirement, we apply the general condition $\operatorname{Tr} \mathbf{J}<0$, Det $\mathbf{J}>0$. For this system, it will be exposed as (15):

$$
\left\{\begin{array}{c}
-\frac{2}{\delta}(\kappa+\Xi)-\frac{1}{M}(P+\Omega)<0 \\
\kappa P+\Xi P+\kappa \Omega>0
\end{array}\right.
$$

As the parameters $\kappa$ and $\Xi$ may only have positive values, the condition (16) is readily satisfied, if the parameters $\mathrm{P}$ and $\Omega$ are also positive. It occurs if the DEL capacitance impacts aren't strong enough to destabilize the system.

If $\mathrm{P}>0$ and $\Omega>0$, the first expression will maintain negative values, and the second expression will remain positive, describing a diffusion-controlled electroanalytical system with a vast parameter region, correspondent to the linear dependence between the concentration of the phenolic compound and the electrochemical parameter (system current). The electroanalytical process may be used in different media, including the mushroom pulp, food, and dye samples and biological liquids. Nevertheless, for electroanalytical purposes, the use of $\mathrm{CoO}(\mathrm{OH})$ $\mathrm{CoO}$ redox pair will be a bit more efficient.

On the other hand, taking into account the polymerization scenario, this system may be used either for electroanalytical or for electrosynthetical purposes. The surface of squaraine dye/ $\mathrm{CoO}(\mathrm{OH}) /$ poly $\left(4,4^{\prime}\right.$-dihydroxyazobenzene $)$ is to be highly conductive and well developed. The morphology of the resulting composite will be centered near Cobalt(III) oxide-hydroxide activated sites.

The monotonic instability, correspondent to the $\mathrm{N}$ shaped part of the voltammogram, delimits the margin between the stable steady-states and unstable states. Its condition for the bivariant systems is $\operatorname{Tr} \mathrm{J}<0$, Det $\mathrm{J}=0$.

$\left\{\begin{array}{c}-\frac{2}{\delta}(\kappa+\Xi)-\frac{1}{M}(P+\Omega)<0 \\ \kappa P+\Xi P+\kappa \Omega=0\end{array}\right.$

Two factors, not included in the simplest model, may also influence the system's behavior.

In the case of the participation of the quinonic product in the chain propagation and interruption, the third equation will be added to the equation-set (1). The polymerization rate equation will also be altered.

Yet if the polymer, yielded during the phenolic compound oxidation, is also oxidized (which is similar to, however, known "polythiophene paradox"), the third equation of other type is also added. Both of the cases will be evaluated in our next works. 


\section{Conclusions}

From the theoretical analysis of the electrochemical determination of the 4-4'-dihydroxyazobenzene, assisted by the $\mathrm{CoO}(\mathrm{OH})$ composite with a squaraine dye, with the use of $\mathrm{CoO}(\mathrm{OH})-\mathrm{CoO}_{2}$ redox pair, it was possible to conclude that:

- The electroanalytical process is highly stable, and the linear dependence between the concentration and electrochemical parameters is realized in a wide parameter range. Nevertheless, comparing to the $\mathrm{CoO}(\mathrm{OH})-\mathrm{CoO}$ redox pair, the stability is lower;

- The diffusion of the phenolic analyte controls the electroanalytical process;

- This system may be used for both electroanalytical and electrosynthetical purposes, yielding a welldeveloped and highly conductive polymer composite;

- The electroanalytical process is efficient and suitable for the determination of 4-4'-dihydroxyazobenzene in different media, including mushroom pulp, food, and biological liquids;

- The oscillatory behavior in this system is possible, being caused by DEL influences of both chemical and electrochemical reactions. The oscillation characteristic will be highly dependent on the nature of the supporting electrolyte.

\section{References}

1- K. Wisitrassameewong, S. C. Karunarathna, N. Thongklang R. Zhao, P. Callac, S. Moukha, C. Ferandon, E. Chukeatirote, K. D. Hyde, Agaricus subrufescens: a review, Saudi J. Biol. Sci., 2012, 19, 131-146.

2- F. Firenzuoli, L. Gori, G. Lombardo, The Medicinal Mushroom Agaricus blazei Murrill: Review of Literature and PharmacoToxicological Problems, Evid. Based Compl. Alt. Med., 2008, 5, 3-15.

3- A. Bhushan, M. Kulshreshtha, The Medicinal Mushroom Agaricus bisporus: Review of Phytopharmacology and Potential Role in the Treatment of Various Diseases, J. Nat. Sci. Med., 2018, 1, 4-9.

4- E. S. Dias, C. Abe, R. Freitas Schwan, Truths and myths about the mushroom Agaricus blazei, Sci. Agric., 2004, 61, 545-549.

5- M. Gill, R. Strauch, Constituents of Agaricus xanthodermus Genevier: The First Naturally Endogenous Azo Compound and Toxic Phenolic Metabolites, Z. Naturforschung, 1984, 39, 1027-1029.

6- K. A. Graeme, Mycetism: A Review of the Recent Literature, J. Med. Toxicol., 2014, 10, 173-189.

7- A. D. L. Lima, R. Costa Fortes, M. Garbi Novaes, S. Percário, Poisonous Mushrooms: A Review of the Most Common Intoxications, Nutr. Hosp., 2012, 27, 402-408.
8- D. A. Ribeiro, D. G. Macedo, L. G. S. de Oliveira M. E. Saraiva, S. F. Oliveira, M. M. A. Souza, I. R. A. Menezes, Potencial terapêutico e uso de plantas medicinais em uma área de Caatinga no estado do Ceará, nordeste do Brasil, Rev. Bras. Plant. Med., 2014, 16, 912-930.

9- F. S. Tian, Y. Chen, H. Liang, Determination of dobutamine hydrochloride by enzymatic catalytic spectrofluorimetry, Luminescence, 2014, 29, 92-95.

10-D. A. F. Silva, M. L. Menezes, W. G. Kempinas, Desenvolvimento e validação de método analítico para determinação simultânea de catecolaminas em órgãos reprodutores de ratos por cromatografia líquida de alta eficiência com detecção electroquímica, Eclét. Quím., 2007, 32, 35-42.

11-M. Sadikoglu, U. Soylu, S. Yilmaz, B. Selvi, H. Y. Seckin, A. Nosal-Wiercinska, Electrocatalytic oxidation of moxifloxacin hydrochloride on modified glassy carbon surface and determination in Avelox tablets, Bulg. Chem. Comm., 2019, 51, 125-133.

12-K. Ahmad, P. Kumar, S. Mobin, A highly sensitive and selective hydroquinone sensor based on a newly designed $\mathrm{N}-\mathrm{rGO} / \mathrm{SrZrO}_{3}$ composite, Nanoscale Adv., 2020, 502-511.

13-L. Scarpetta, A. Mariño, K. Bolaños Y. Leiva, P. Castiblanco, É. Nagles, Determinación de hidroquinona usando un electrodo de carbono vítreo modificado con quitosano, nanotubos de carbono de pared múltiple y líquido iónico, Rev. Colomb. Cien. Quím. Farm., 2015, 44, 311-322.

14-J. B. Raoof, A. Kiani, R. Ojani, R. Valliolahi, Electrochemical Determination of Dopamine Using Banana-MWCNTs Modified Carbon Paste Electrode, Anal. Bioanal. Electrochem., 2011, 3, 59-66.

15-M. Burç, Ö. Güngör, S. Titretir Duran, Voltammetric Determination of Curcumin in Spices using Platinum Electrode Electrochemically Modified with Poly (Vanillinco-Caffeic Acid), Anal. Bioanal. Electrochem., 2020, 12, 625-643.

16-M. S. Burke, M. G. Kast, L. Trotochaud A. M. Smith, S. W. Boettcher, Cobalt-iron (Oxy)hydroxide Oxygen Evolution Electrocatalysts: The Role of Structure and Composition on Activity, Stability, and Mechanism, J. Am. Chem. Soc., 2015, 137, 3638-3648.

17-C. J. Raj, B. Ch. Kim, W. J. Cho S. Park, H. T. Jeong, K. Yoo, K. H. Yu, Rapid hydrothermal synthesis of Cobalt oxyhydroxide nanorods for supercapacitor applications, J. Electroanal. Chem., 2015, 747, 130-136.

18-M. Kang, H. Zhou, N. Zhao, B. Ly, Porous $\mathrm{Co}_{3} \mathrm{O}_{4}$ nanoplates as an efficient electromaterial for non-enzymatic glucose sensing, CrystEngComm., 2020, 22, 35-43. 
19-A. Stadnik, E. M. Caldas, A. Galli, F. J. Anaissi, Eletrodo modificado com $[\mathrm{CoO}(\mathrm{OH})]$ coloidal aplicado na detecção de ácido oxálico, Orbital. Elec. J. Chem., 2015, 7, 122-126.

20-J. S. Bonini, F. Q. Mariani, E. Guimarães Castro, A.Galli, R. Marangoni, F. J. Anaissi, Partículas de $\mathrm{CoO}(\mathrm{OH})$ dispersas em pasta de carbono aplicado na eletrooxidação de compostos fenólicos, Orbital Elec. J. Chem., 2015, 7, 318-322.

21-S. Tursynbolat, Y. Bakytkarim, J. Huang, L. Wang, Ultrasensitive Electrochemical Determination of Metronidazole Based on polydopamine/carboxylic Multi-Walled Carbon Nanotubes Nanocomposites Modified GCE, J. Pharm. Anal., 2018, 8, 124-128.

22-H. Li, L. Zhang, Y. Mao, C. Wen, P. Zhao, A Simple Electrochemical Route to Access Amorphous Co-Ni Hydroxide for NonEnzymatic Glucose Sensing, Nanoscale Res. Lett., 2019, 14, 135-143.

23-Volodymyr V. Tkach, Marta V. Kushnir, Nataliia M. Storoshchuk, Volodymyr V. Parchenko, Ilona I. Aksyonova, Vira M. Odyntsova, Olga V. Luganska, and Petro I. Yagodynets, The Theoretical Description of Cathodic Deposition of New Conducting Polymer Composite, Assisted by a Perrhenate of a Novel Triazolic Derivative, Orbital: The Electronic Journal of Chemistry, 2020, 12(2),
DOI: http://dx.doi.org/10.17807/orbital.v12i2.11 93.

24-V.V. Tkach, Ya. G. Ivanushko, S.M. Lukanova, L. V. Romaniv, I. Kukovs'ka, S. C. de Oliveira, R. Ojani, F. J. Anaissi, P. I. Yagodynets, The Mathematical Description for $\mathrm{CoO}(\mathrm{OH})$-Assisted Hydroxylamine Electrochemical Determination in Neutral Media, Iran. J. Chem. Chem. Eng., 2018, 37, 111-115.

25-V.V. Tkach, Ya. G. Ivanushko, S. M. Lukanova et al., The mathematical description, assisted by $\mathrm{CoO}(\mathrm{OH})$ - Conducting Polymer Composite, Appl. J. Env. Eng. Sci., 2017, 3, 333-340.

26-V.V. Tkach, L.V. Romaniv, S. M. Lukanova, S. C. de Oliveira, R. Ojani, F. J. Anaissi, P. I. Yagodynets, The possibility of nalbuphine $\mathrm{CoO}(\mathrm{OH})$-assisted electrochemical detection and its mathematical description, Alb. J. Pharm. Sci., 2016, 3, 8-11.

27-O. Stadnik, N. Ivanova, Y. Boldyrev, 218th Int. Electrochem. Soc. Meeting. Abstract \# 2240, http://ma.ecsdl.org/content/MA201002/38/2240.full.pdf Accessed at 8th of August 2015.

28-O. Stadnik, Synthesis, Electrochemical and Photoelectrochemical Properties of the Oxidehydroxide Compounds of Cobalt, Diss. Kand. Chim. N. Kyiv, 2011. 